\title{
Analyzing and Discussing the Steady-State Error for Nonentity Feedback Control System by Type Number
}

\author{
Y.C. Kuo, S.C. Mou \\ Department of Mechanical Engineering \\ Chien Hsin University of Science and Technology \\ Taiwan
}

\begin{abstract}
This study is based on the method of analyzing the steady-state errors of the traditional unity feedback control systems. The method in this study combines the concept of type number and the new error function offered by Kuo. In this study, the definition of type number will be revised. The new definition of type number is useful and correct in unity feedback control systems and nonunity feedback control systems. Thus, the steadystate errors of nonunity feedback control systems can be obtained directly by this method.
\end{abstract}

Keywords-nonentity feedback; steady-state error; type numbe; error function

\section{INTRODUCTION}

The most important merit of the feedback control systems is that it enables adjustment of the transient response, and the sensitivities and the disturbances of the systems can be decreased by this adjustment of the transient response. Checking the steady-state error [1-5] is another method to use if there is any special requirement to the systems. The steadystate error is the error which occurs after the transient response.
The purpose of the steady-state error to a system is to enable not only the adjustment of the transient response, but also measurement of the capability of the system. There are many factors that are not easy to prevent, such as the effect of friction and the exhalation of thermal energy. Hence, the steady-state errors of the systems are seldom zero in reality, but the steady-state errors of the systems should be considered when designing a control system. The definition of the steadystate error is the difference between the input signal and the output signal while the system is in stable time. The steadystate error of the systems is seldom zero in reality, but the steady-state error of the system should be thought over by designing a control system, and the accuracy of the control system depends on the purpose of the control.

In the closed-loop control system in fig 1 as long as the closed-loop control system is a unity feedback control system $(\mathrm{H}(\mathrm{s})=1), \mathrm{r}(\mathrm{t})$ is the input signal, $\mathrm{y}(\mathrm{t})$ is the output signal, and the error function of the system is shown as $\mathrm{e}(\mathrm{t})=\mathrm{r}(\mathrm{t})-\mathrm{y}(\mathrm{t})$, and the steady-state error can be defined as

$$
e_{s s}=\lim _{t \rightarrow \infty} e(t)=\lim _{s \rightarrow 0} s E(s)=\lim _{s \rightarrow 0} s[R(s)-Y(s)]=\lim _{s \rightarrow 0} s\left[\frac{1}{1+G(s)}\right] R(s)
$$

According to eqn (1), the steady-state errors of unity feedback control systems relate to the forward-path transfer function $\mathrm{G}(\mathrm{s})$ and the input signal $\mathrm{R}(\mathrm{s})$. The method of obtaining type number is to observe the forward-path transfer function $\mathrm{G}(\mathrm{s})$ so that different type numbers and different input signals will cause different steady-state errors. When the input signals are step function, ramp function and parabolic function, the steady-state errors can be expressed as

$$
\begin{aligned}
& e_{s s(s t e p)}=\lim _{s \rightarrow 0} \frac{s}{1+G(s)} \times \frac{R}{s}=\lim _{s \rightarrow 0} \frac{R}{1+G(s)}=\frac{R}{1+\left[\lim _{s \rightarrow 0} G(s)\right]} \equiv \frac{R}{1+K_{P}} \\
& e_{s s(\text { ramp })}=\lim _{s \rightarrow 0} \frac{s}{1+G(s)} \times \frac{R}{s^{2}}=\lim _{s \rightarrow 0} \frac{R}{s G(s)}=\frac{R}{\lim _{s \rightarrow 0} s G(s)} \equiv \frac{R}{K_{V}} \\
& e_{s s(\text { parabolic) }}=\lim _{s \rightarrow 0} \frac{s}{1+G(s)} \times \frac{R}{s^{3}}=\lim _{s \rightarrow 0} \frac{R}{s^{2} G(s)}=\frac{R}{\lim _{s \rightarrow 0} s^{2} G(s)} \equiv \frac{R}{K_{a}}
\end{aligned}
$$

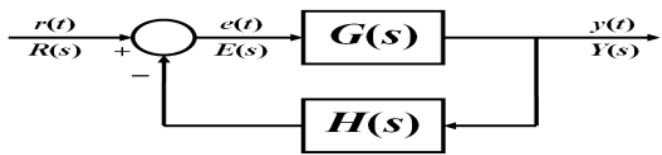

FIGURE I. THE BLOCK DIAGRAM OF FEEDBACK CONTROL SYSTEMS 
$\mathrm{K}_{\mathrm{p}}$ is the position error constant; the definition of the position error constant is $K_{p} \equiv \lim _{s \rightarrow 0}[G(s)]$. $K_{V}$ is the velocity error constant; the definition of the velocity error constant is $\mathrm{K}_{\mathrm{V}} \equiv \lim _{\mathrm{s} \rightarrow 0}[\mathrm{sG}(\mathrm{s})] . \mathrm{K}_{\mathrm{a}}$ is the acceleration error constant; the definition of the acceleration error constant is $\mathrm{K}_{\mathrm{a}} \equiv \lim _{\mathrm{s} \rightarrow 0}\left[\mathrm{~s}^{2} \mathrm{G}(\mathrm{s})\right]$. The relationship between the input signals and the type number on the steady-state errors can be summarized in table $1[2,3,5]$. Three conditions can be easily concluded from table 1. (1). The steady-state error of the closed-loop system must be zero when the type number of the system is higher than the order of the input signal (the order of the step input is zero; the order of the ramp input is one, and the order of the parabolic input is two). The error effect, which is produced by the input signal, can be eliminated completely by the system. In other words, the anti-disturbance ability of the system is higher than the disturbance of the input signal, and therefore, the steady-state error must be zero. (2). The steady-state error of the closed-loop system must be infinity when the type number of the system is lower than the order of the input signal. The error effect which is produced by the input signal can not be eliminated completely by the system. In other words, the anti-disturbance ability of the system is lower than the disturbance of the input signal, and therefore, the steady-state error must be infinity. (3). The steady-state error of the closed-loop system must be a finite value (it is impossible for it to be zero and infinity) when the type number of the system is equal to the order of the input signal. The part of the error effect which is produced by the input signal can be eliminated by the system, in other word, the anti-disturbance ability of the system is similar to the disturbance of the input signal; the steady-state error must be a finite value.

\section{DEFINITION OF NEW TYPE NUMBER}

Traditionally, the definition of system type number is dependent on the forward path transfer function $\mathrm{G}(\mathrm{s})$, it can be expressed for convenience as

$$
G(s)=\frac{K\left(1+T_{1} s\right)\left(1+T_{2} s\right) \cdots\left(1+T_{m} s\right)}{s^{N}\left(1+T_{a} s\right)\left(1+T_{b} s\right) \cdots\left(1+T_{n} s\right)}
$$

TABLE I. SUMMARY OF THE STEADY-STATE ERROR TO DIFFERENT INPUTS FOR UNITY FEEDBACK SYSTEMS

\begin{tabular}{|c|c|c|c|c|c|c|c|c|}
\hline \multirow{2}{*}{ Type of System } & \multicolumn{3}{|c|}{ Error Constants } & \multirow{2}{*}{$\begin{array}{l}\text { Step } \\
R /\left(1+K_{p}\right)\end{array}$} & \multirow{2}{*}{ Input } & \multirow{2}{*}{ Ramp Input $\mathrm{R} / \mathrm{K}_{\mathrm{V}}$} & \multirow{2}{*}{$\begin{array}{l}\text { Parabolic } \\
\mathrm{R} / \mathrm{K}_{\mathrm{a}}\end{array}$} & \multirow[t]{2}{*}{ Input } \\
\hline & $\mathrm{K}_{\mathrm{p}}$ & $\mathrm{K}_{\mathrm{V}}$ & $\mathrm{K}_{\mathrm{a}}$ & & & & & \\
\hline 0 & $\mathrm{~K}$ & 0 & 0 & $\mathrm{R} /(1+\mathrm{K})$ & & $\infty$ & $\infty$ & \\
\hline 1 & $\infty$ & $\mathrm{K}$ & 0 & 0 & & $\mathrm{R} / \mathrm{K}$ & $\infty$ & \\
\hline 2 & $\infty$ & $\infty$ & $\mathrm{K}$ & 0 & & 0 & $\mathrm{R} / \mathrm{K}$ & \\
\hline 3 & $\infty$ & $\infty$ & $\infty$ & 0 & & 0 & 0 & \\
\hline
\end{tabular}

Type number can be determined by observing the constant $\mathrm{N}$ of $\mathrm{G}(\mathrm{s})$, and the poles and zeros of $\mathrm{G}(\mathrm{s})$ at $\mathrm{s}=0$ must cancel each other before the constant $\mathrm{N}$ is determined. The forward path transfer function can be re-written as

$$
e_{s s}=\lim _{s \rightarrow 0} s\left[\frac{1}{1+G(s)}\right] R(s)=\lim _{s \rightarrow 0} s\left[\frac{s^{N} \times \operatorname{den}(s)}{s^{N} \times \operatorname{den}(s)+\operatorname{num}(s)}\right] R(s)
$$

In a comparison of the original expression with the new expression shown in eqn (6)[6], type number can be found in the original expression $\mathrm{G}(\mathrm{s})$ first, and then analyzing the steady-state error of the system, and the new expression is observing type number by $[1+\mathrm{G}(\mathrm{s})]^{-1}$ first, and then analyzing the steady-state error of the system. The original type number is determined by the number of poles of $\mathrm{G}(\mathrm{s})$ has at $\mathrm{s}=0$, but the new type number is determined by the number of zeros of $[1+\mathrm{G}(\mathrm{s})]^{-1}$ has at $\mathrm{s}=0$.

In general, type number is seldom determined by observing $[1+G(s)]-1$ when analyzing the steady-state errors of unity
$\mathrm{G}(\mathrm{s}) \equiv \operatorname{num}(\mathrm{s}) /\left[\mathrm{s}^{\mathrm{N}} \times \operatorname{den}(\mathrm{s})\right]$. Thus, type number is still maintain as $\mathrm{N}$, and the steady-state errors of unity feedback control systems can be expressed as

feedback control systems because $\mathrm{G}(\mathrm{s})$ is usually known in the systems, and $[1+\mathrm{G}(\mathrm{s})]-1$ is usually known after calculating. But this concept can be extended to nonunity feedback control systems. For instance, type number can not be determined only by observing $\mathrm{G}(\mathrm{s})$ because the feedback path transfer functions $\mathrm{H}(\mathrm{s})$ exist in nonunity feedback control systems. Therefore, type number can be determined by the number of zeros of $[1+\mathrm{G}(\mathrm{s})]-1$ has at $\mathrm{s}=0$.

Combining the concept of eqn (6) and the new error function offered by Kuo, the steady-state error can be rewritten as 


$$
\begin{aligned}
e_{s s} & =\lim _{s \rightarrow 0} s E(s)=\lim _{s \rightarrow 0} s\left[\frac{1}{K_{H}} R(s)-Y(s)\right] \\
& =\lim _{s \rightarrow 0} s\left[\frac{1}{K_{H}}-\frac{G(s)}{1+G(s) H(s)}\right] R(s) \equiv \lim _{s \rightarrow 0} s\left[\frac{1}{K_{H}}-M(s)\right] R(s) \\
& =\lim _{s \rightarrow 0} s\left\{\frac{1}{K_{H}}\left[1-K_{H} M(s)\right]\right\} R(s)
\end{aligned}
$$

In eqn (6), type number is determined by the number of zeros of $[1+G(s)]-1$ has at $s=0$, and in eqn (7), the concept is used in the same way. Type number can be determined by the number of zeros of $[1-\mathrm{KHM}(\mathrm{s})] / \mathrm{KH}$ has at $\mathrm{s}=0$. In other words, it is determined by observing the order of the numerator of [1$\mathrm{KHM}(\mathrm{s})] / \mathrm{KH}$.

Additionally, $\mathrm{KH}=\operatorname{lims} \rightarrow 0[\mathrm{H}(\mathrm{s})]=\mathrm{H}(0)=$ constant. $\mathrm{KH}$ is the direct current gain so that type number can only be determined by the number of zeros of $[1-\mathrm{KHM}(\mathrm{s})]$ has at $\mathrm{s}=0$.

\section{CALCULATION OF THE STEADY-STATE ERROR}

According to the basic theorem of the steady-state error, the steady-state error can be analyzed by the new error function offered by Kuo because the new error function of the systems is the factor of affecting the error. The method of analyzing the steady-state errors of nonunity feedback control systems is like the method of analyzing the steady-state errors of unity feedback control systems ${ }^{5}$. In eqn (7), $M(s)$ is the closed-loop transfer function, $Y(s) / R(s)$, and the form is

$$
M(s)=\frac{b_{m} s^{m}+m_{m-1} s^{m-1}+\cdots+b_{1} s+b_{0}}{s^{n}+a_{n-1} s^{n-1}+\cdots+a_{1} s+a_{0}}
$$

Where $n>m$ and all the poles of $M(s)$ are must in the lefthalf s-plane, and system is stable. The steady-state error can be tested by the different input signals, and the values of steady- state errors will be changed with the different input signals. The three examples illustrate the effects of the different input signals and the type number on the steady-state errors.

$$
\begin{aligned}
e_{s s \text { step })} & =\lim _{s \rightarrow 0} s\left\{\frac{1}{K_{H}}\left[1-K_{H} M(s)\right]\right\} R(s) \\
& =\lim _{s \rightarrow 0} \frac{1}{K_{H}}\left[\frac{\left.s^{n}+\cdots+\left(a_{1}-b_{1} K_{H}\right) s+\left(a_{0}-b_{0} K_{H}\right)\right]}{s^{n}+a_{n-1} s^{n-1}+\cdots+a_{1} s+a_{0}}\right] R \\
& =\frac{1}{K_{H}}\left(\frac{a_{0}-b_{0} K_{H}}{a_{0}}\right) R \\
e_{s s(\text { ramp })} & =\lim _{s \rightarrow 0} \frac{1}{K_{H}}\left\{\frac{s\left[s^{n-1}+\cdots+\left(a_{2}-b_{2} K_{H}\right) s+\left(a_{1}-b_{1} K_{H}\right)\right]}{s^{n}+a_{n-1} s^{n-1}+\cdots+a_{1} s+a_{0}}\right\} \frac{R}{s} \\
= & \frac{1}{K_{H}}\left(\frac{\left.a_{1}-b_{1} K_{H}\right)}{a_{0}}\right) R \\
e_{s s(\text { parabolic) }} & \lim _{s \rightarrow 0} \frac{1}{K_{H}}\left\{\frac{s^{2}\left[s^{n-2}+\cdots+\left(a_{3}-b_{3} K_{H}\right) s+\left(a_{2}-b_{2} K_{H}\right)\right]}{s^{n}+a_{n-1} s^{n-1}+\cdots+a_{1} s+a_{0}}\right\} \frac{R}{s^{2}} \\
= & \frac{1}{K_{H}}\left(\frac{a_{2}-b_{2} K_{H}}{a_{0}}\right) R
\end{aligned}
$$

The results of nonunity feedback control systems are like the results of unity feedback control systems can be summarized in table 2. First, the steady-state errors must be zero when the type number is higher than the order of the input signal. The error effect can be eliminated completely. In other words, the anti- disturbance ability is higher than the disturbance, and therefore, the steady-state error must be zero. Second, the steady-state error must be infinity when the type number is lower than the order of the input signal. The error effect can not be eliminated completely. In other words, the anti-disturbance ability is lower than the disturbance, and therefore, the steady-state error must be infinity. Third, the steady-state errors must be a finite value when the type number is equal to the order of the input signal. The part of the error effect can be eliminated by the system; in other words, the anti-disturbance is similar to the disturbance, and therefore, the steady-state error must be a finite value. 


\section{PROOF AND DISCUSSION}

Table 1 shows the steady-state errors to the different inputs for unity feedback control systems, in the same way; table 2 shows the steady-state errors to different inputs for nonunity feedback control systems. Furthermore, to compare table 1 with table 2, the method of analyzing the steady-state errors of nonunity feedback control systems also can be used to analyze the steady-state errors of unity feedback control systems because unity feedback systems are the one of the cases of

$$
M(s)=\frac{G(s)}{1+G(s)} \Rightarrow M(s)+M(s) G(s)=G(s) \Rightarrow G(s)=\frac{M(s)}{1-M(s)}
$$

TABLE II. SUMMARY OF THE STEADY-STATE ERROR TO DIFFERENT INPUTS FOR NONUNITY FEEDBACK SYSTEMS.

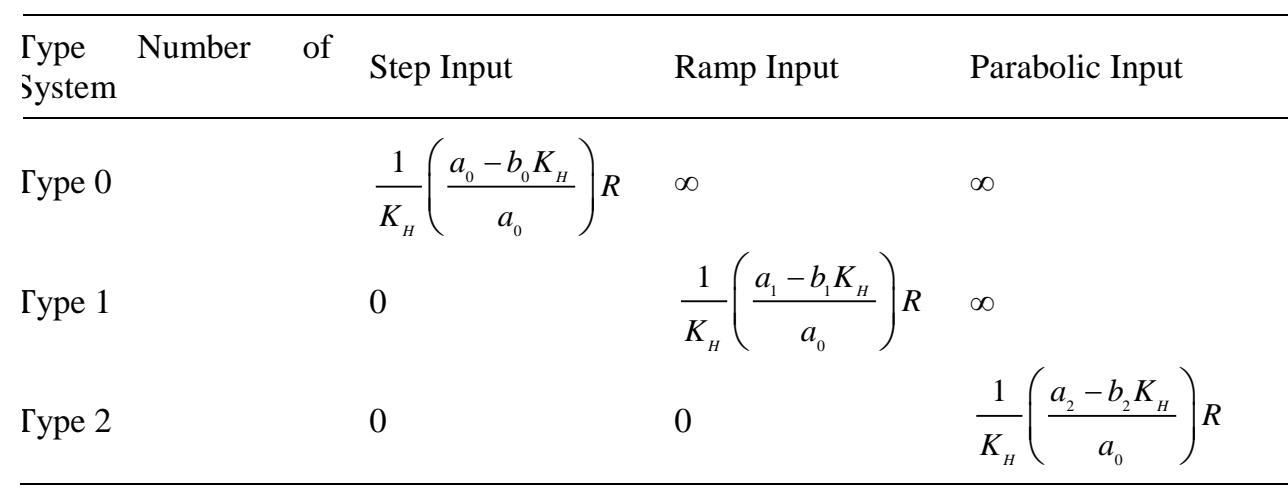

Thus the steady-state error can be calculated by using the equations before, and the steady-state error is (the input signal

is step function)

$$
\begin{aligned}
e_{s s(s e p)} & =\lim _{s \rightarrow 0} s\left[\frac{1}{1+G(s)}\right] R(s)=\lim _{s \rightarrow 0} \frac{R}{1+\frac{M(s)}{1-M(s)}}=\lim _{s \rightarrow 0}[1-M(s)] R \\
& =\lim _{s \rightarrow 0}\left\{\left[\frac{s^{n}+a_{n-1} s^{n-1}+\cdots+\left(a_{1}-b_{1}\right) s+\left(a_{0}-b_{0}\right)}{s^{n}+a_{n-1} s^{n-1}+\cdots+a_{1} s+a_{0}}\right]\right\} R=\left(\frac{a_{0}-b_{0}}{a_{0}}\right) R
\end{aligned}
$$

To compare eqn (10) with eqn (13), the difference is only based on $K_{H}$ of feedback control system, and the $K_{H}$ of unity feedback control system must be one. Hence, eqn (10) and eqn (13) are the same, this method can be applied to the ramp input and parabolic input, and the method in this study is correct, so this method can be used to analyze the steady-state errors of both unity and nonunity feedback systems in an easy and accurate way.

Finally, the common method of analyzing the steady-state errors of nonunity feedback control systems will be discussed. If nonunity feedback control systems are converted into equivalent unity feedback control systems, the concept of type number would be used to calculate the steady-state errors of the systems. The calculation is shown as

$$
\begin{aligned}
e_{s s(\text { unity feectacec })} & =\left.\lim _{s \rightarrow 0} s\left[\frac{1}{1+G_{e}(s)}\right] R(s)\right|_{G_{e}(s)=\frac{G(s)}{1+G(s) H(s)-G(s)}} \\
& =\lim _{s \rightarrow 0} s\left[\frac{1+G(s) H(s)-G(s)}{1+G(s) H(s)}\right] R(s)
\end{aligned}
$$

If nonunity feedback control systems are not converted into equivalent unity feedback control systems, the steadystate errors are calculated by using the relationship between input signals and output signals, then the error function of the system $\mathrm{E}(\mathrm{s})=\mathrm{R}(\mathrm{s})-\mathrm{H}(\mathrm{s}) \mathrm{Y}(\mathrm{s}) \mathrm{R}(\mathrm{s})$ is not equal to the error $e_{s s(\text { nomminty fectiack })}=\lim _{s \rightarrow 0} s[R(s)-H(s) Y(s)]=\lim _{s \rightarrow 0} s\left[\frac{1}{1+G(s) H(s)}\right] R(s)$ function which is usually used as $\mathrm{E}(\mathrm{s})=\mathrm{R}(\mathrm{s})-\mathrm{Y}(\mathrm{s})$, and transfer function $\mathrm{Y}(\mathrm{s}) / \mathrm{R}(\mathrm{s})=\mathrm{G}(\mathrm{s}) /[1+\mathrm{G}(\mathrm{s}) \mathrm{H}(\mathrm{s})]$ is not equal to the function $Y(s) / R(s)=G(s) /[1+G(s)]$, either. The steady-state error is

To compare eqn (14) with eqn (15), the results of these two methods are different, but the results are based on the 
same nonunity feedback control system; the most important reason why the results are different is the definition of error function is not correct, in other words, the position where error occurs is not clear by using the common method. If the results must be the same, the following formula must be satisfied

$$
\lim _{s \rightarrow 0} \frac{1+G(s) H(s)-G(s)}{1+G(s) H(s)}=\lim _{s \rightarrow 0} \frac{1}{1+G(s) H(s)}
$$

Thus, eqn (16) is true only in these two hypotheses follows; (1) the feedback path transfer function is one $(\mathrm{H}(\mathrm{s})=1)$. (2) If the feedback path transfer function is not one, the direct current gain of the system must be one $(\mathrm{KH}=1)$. To sum up, the common method is only used to calculate the steady-state errors of the nonunity feedback control systems with the direct current gain of the system is one, and it can not be used to calculate the steady-state errors of the other feedback control systems.

\section{CONCLUSIONS}

Using the method offered by this study of analyzing the nonunity feedback control system can determine type number and calculate the steady-state error of the system directly. The advantages of this method can be known as four parts. First, determining the type number of nonunity feedback control system by this study, and the traditional method cannot determine it directly. Second, the table of the nonunity feedback control system can be established by this study such as the table of the unity feedback control system can be established before. Third, using this method can simplify the calculation of the steady-state error and the hypotheses in Kuo's book can be avoided. Fourth, the traditional common method of analyzing the steady-state errors of the nonunity feedback control systems is not complete correctness. The common method is only correct in the system with the direct current gain is one.

\section{REFERENCES}

[1] Drof, R.C., \& Bishop, R.H, Modern control systems, 12th ed., Prentice Hall: New Jersey, pp. 272-275, 2011.

[2] Ogata, K., Modern control engineering, 4th ed., Prentice Hall: New Jersey, pp. 288-293, 2002.

[3] Franklin, G.F., Powell, J.D., \& Naeini, A.E., Feedback control of dynamic systems, 4th ed., Prentice Hall: New Jersey, pp. 230-244, 2002.

[4] Nise, N.S., Control systems engineering, 6th ed., John Wiley \& Sons: New Jersey, pp. 358-362, 2011.

[5] Kuo, B.C., \& Golnaraghi, F., Automatic control systems, 9th ed., John Wiley \& Sons: New Jersey, pp. 258-274, 2008.

[6] Mou, S.C., Verifying and simulating of the novel analytical method of the steady-state error for nonunity feedback control systems. Advanced materials research, 301-303, pp. 1670-1675, 2011. 